Supporting Information

\title{
Reactivity Control of Rhodium Cluster Ions by Alloying with Tantalum Atoms
}

\section{Fumitaka Mafuné*, Yuki Tawaraya, Satoshi Kudoh}

Department of Basic Science, School of Arts and Sciences, The University of Tokyo, Komaba, Meguro, Tokyo 153-8902, Japan

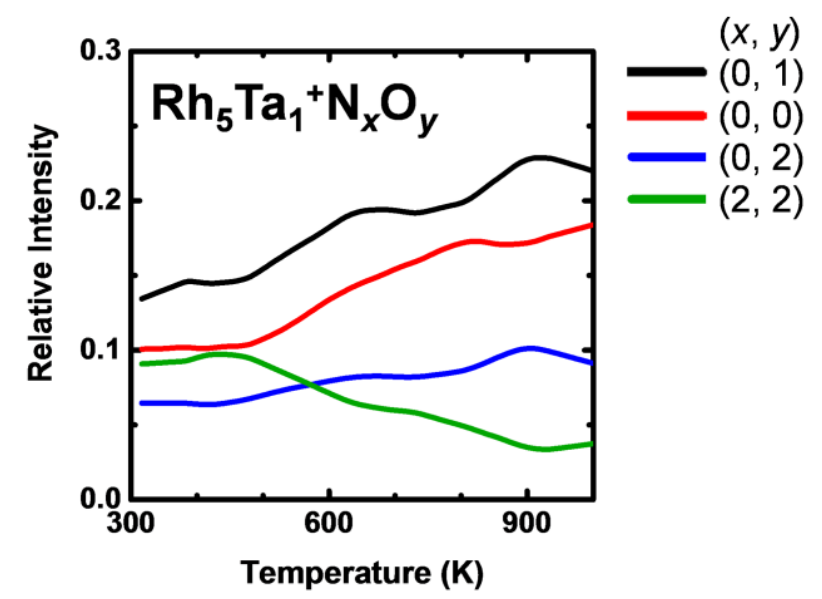

Figure S1 TDS plots showing relative ion intensities of $\mathrm{Rh}_{5} \mathrm{Ta}^{+} \mathrm{N}_{x} \mathrm{O}_{x}(x=0$ and 2) and $\mathrm{Rh}_{5} \mathrm{Ta}^{+} \mathrm{O}_{x}(x=1$ and 2$)$ as a function of temperature. 